\title{
Cacaso não é bem o caso do acaso $^{1}$
}

Milena Magalhães

1.

Tudo indica que a poesia de Cacaso esteja se firmando no cenário brasileiro como um dos acontecimentos mais importantes da chamada poesia marginal. O que talvez não queira dizer muito, se atentarmos para o fato de que, em prejuízo do reconhecimento de sua poesia como manifestação artística, coloca-se em primeiro plano apenas a sua relevância como representante de um movimento. Especificamente, essa poesia, em geral, é vista como marcada por um profundo "hedonismo", em um conseqüente abandono da pesquisa formal, tendo sido esta substituída pela expressividade espontânea dos acontecimentos cotidianos, mas sem o caráter de inventividade que marcou a corrente modernista do início do século XX.

Quando se fala em poesia do cotidiano no Brasil, é inevitável não retornar a esse movimento que, de certo modo, autenticou e demarcou os limites do que seria uma poesia voltada para a experiência vivida. O Manifesto da Poesia Pau-Brasil tem início justamente com o que virou a máxima modernista: "A poesia existe nos fatos". Numa antecipação adivinhatória da grande metrópole em que São Paulo se transformaria, Mário de Andrade poetizou a imagem modernizante da cidade ${ }^{2}$, a partir de certa horizontalidade da palavra que pretendia suspender os artifícios da linguagem poética. Tal efeito é ainda maior no fragmentário, nas experimentações lingüísticas e na tirada humorística do poema-piada de Oswald de Andrade ${ }^{3}$. A visada poética de Manuel Bandeira, ao aproximar o lirismo do prosaico, amarrou a miudeza, a "desimportância" dos fatos

\footnotetext{
${ }^{1}$ Este artigo teve a valiosa contribuição das dicas de leitura feitas por Marcos Siscar e Rubens Vaz Cavalcante (Binho).

2 "Minha Londres das neblinas finas!/ Pleno verão. Os dez mil milhões de rosas paulistanas" (Andrade, Mário de. Poesias completas. Belo Horizonte: Villa Rica, 1993: 87).

s "Meu amor me ensinou a ser simples/ Como um largo de igreja/ Onde não há nem um sino/ Nem um lápis/ Nem uma sensibilidade” (Andrade, Oswald de. Pau Brasil. São Paulo: Globo/ Secretaria de Estado da Cultura, 1990).
} 
"(Cf. Simon, lumna Maria \& Dantas, Vinicius. "Poesia ruim, sociedade pior", Novos Estudos CEBRAP n. 12, São Paulo, 1985 ; Simon, lumna Maria. "Es teticismo e participação: as vanguardas poéticas no contexto brasileiro (1954 1969)". Em: Pizarro, Ana (org.). América latina: pa lavra, literatura e cultura. São Paulo / Campinas: Memorial da América La tina / Unicamp, 1995: 335.63). a uma expressão natural e desafetada ${ }^{4}$. O prazer da sua leitura está aliado a uma certa inflexão da voz. É o momento em que o texto escrito agrega os modos da fala. Tudo anunciado em sua Poética: "Estou farto do lirismo comedido/ do lirismo bem comportado".

Passados mais de oitenta anos do início do movimento modernista, a ruptura causada por esses escritores já foi absorvida pela academia. Tendo sido esmiuçados seus livros e o período do qual fizeram parte, reconhecemos nesses escritores tanto o valor artístico das suas obras quanto a importância das atualizações promovidas por eles no verbete literatura. A "poesia marginal” não tem tido a mesma sorte. Em alguns setores da nossa inteligência nacional, ainda é vista de forma depreciativa, sinônimo de inferior, à margem, desimportante e mesmo como parte do encerramento daquilo que constituiu a atualização da poesia no Brasil. Aparentemente, essa imagem preconcebida se ancora na defesa de uma "qualidade" poética que teria sido relegada por esses poetas*. A meu ver, tais análises derivam do esquecimento de que a escolha por transpor a vivência ordinária para o texto poético implica inevitavelmente uma mudança de e na linguagem. Invariavelmente, essas leituras têm como fundo a História, uma certa idéia de história que exerce a função de demarcar a evolução dos acontecimentos, neste caso, poéticos. A partir daí, delibera-se que a produção dessa época é tão-somente a transposição literal dos fatos para livros mimeografados ou feitos manualmente, sem valor literário. Se, à época, foi anunciado que se estava à procura de uma "auto-expressão imediata, elementar, espontânea”, em flagrante uso da crítica como mera duplicação da palavra do artista, convencionou-se lê-la do mesmo modo, mas para subestimá-la, ignorando-se o que estava em jogo no uso dessa nova linguagem ${ }^{5}$.

Em relação ao poeta Cacaso, portanto, é falaciosa a afirmação de que a sua poesia, ao optar pelo não-distanciamento

4 “...Bebeu/ Cantou/ Dançou/ Depois se atirou na Lagoa Rodrigo de Freitas e morreu afogado” (Bandeira, Manuel. Libertinagem छ Estrela da manhã. Rio de Janeiro: Nova Fronteira, 2000: 46).

5 "Descobre-se que a poesia existe em tudo, e tudo pode ser poesia. É claro que, num momento desses, do ponto de vista da poesia em si mesma, é natural que haja um rebaixamento do nível de qualidade artística. Uma desqualificação da arte. Mas essa desqualificação vai ter um peso muito relativo e um valor tático, e em certo sentido passa a ser secundário”. Brito, A. C. F. de (Cacaso). Não quero prosa (Campinas/Rio de Janeiro: Editora da Unicamp/Editora da UFRJ, 1997: 324). 
das situações cotidianas, prescindiu de elaboração poética. Essa premissa, se posta como medida para desvalorização da sua poesia, não encontra acolhida no conjunto de sua obra. É mais certo que a busca por uma "auto-expressão imediata” nos deva reconduzir às discussões que questionam em que momento se dá a passagem de uma linguagem “ordinária” para outra "literária", representando as aspas aqui a dificuldade de denominá-las e distingui-las.

Como todo grande escritor, Cacaso participou ativamente das discussões do seu tempo. Foi contemporâneo de todas as bossas e balanços, e afirmou em prosa e verso suas influências. Com seu jeito mineiro, esteve em busca "de uma perspectiva mais adequada e mais justa” tanto para a sua poesia quanto para a de outrem. A suposta opção pelas miudezas do cotidiano é remarcada de diversos modos no corpo de sua poesia, colocando em suspensão o que quer dizer afirmar que esta ou aquela poesia é voltada para o cotidiano, uma vez que ela é também intermediada pela memória do sujeito lírico. Seus poemas apontam para a construção de um simulacro de espontaneidade, sustentado por uma depuração da linguagem que se aproxima do mínimo, do quase silêncio. Mais do que das conversas cotidianas, a poesia de Cacaso se aproveita dos intervalos, das pausas, dessas conversas.

Um dos caminhos para entender essa produção é repensar a idéia de poesia veiculada por ela; atenta a esse sentido, seria inócua qualquer crítica que queira lhe dar um parâmetro, fazendo uso dos modelos analíticos convencionais. Boa parte dos que estavam envolvidos na produção poética da segunda metade do século XX não apenas fez do cotidiano a sua matéria poética, mas antes poetizou esse cotidiano, o que inevitavelmente aproximou a dualidade vida/criação, promovendo, na feitura do poema, o afastamento dos recursos literários institucionalizados e a aproximação com a língua falada. A intenção estava no gesto, pronto para ser transformado em palavra. É a época do desbunde, da liberação de todos os recalques, que marca um lugar de afronta - ou não - ao estado de exceção então existente no Brasil. Há momentos em que, sob a pressão da história, o impulso das transformações pode ser percebido no exato instante em que acontece, e as décadas de 1960 e 1970 foram um desses momentos. As novas formas de vida surgidas nesse período repercutem ainda hoje. O movimento que ocorreu em algumas cidades brasileiras de pessoas irem às ruas, aos bares, 
"(Pereira, Carlos Alberto Messeder. Retrato de época: poesia marginal anos 70 Rio de Janeiro: Funarte, 1981: 144). aos shows, aos cinemas, com o objetivo de vender, trocar ou comprar poesia remarcava um sentido de grupo, advindo de uma vivência tribal ligada ao instinto de sobrevivência. Daí ser fácil supor que a busca por uma proximidade com o público leitor interferiu na produção. Atitude que não é nova, nem inovadora. Muitos dos mais aclamados escritores escreveram "por encomenda”, tendo um determinado público no horizonte. Hoje, mesmo quando se admite tal fato, ressalva-se que, embora tenham sido essas as condições, não houve barateamento em suas produções. Não é costume, contudo, afirmar o mesmo em relação aos "marginais", entre outras razões porque a atitude de eleger outros parâmetros para a poesia põe sob tensão de forma acintosa o próprio sentido da poesia. Embora no modelo até então naturalizado de poesia coubessem linguagens diferenciadas, como as de Drummond, Cabral, Mário de Andrade, Haroldo de Campos etc., causou assombro - e ainda causa um tipo de linguagem que aparentemente nega toda e qualquer filiação, aproximando-se do inacabamento da fala. Essa negação ao convencional, presente no modo de constituição da sua poesia, é o que hoje estabelece a ordem de valores que a denomina “poesia ruim”. Mas, em Cacaso, é justamente esse gesto que desnaturaliza o conceito de literatura.

Afora o reconhecimento dessas questões, não é sem ressalva que aplicamos a alcunha de marginal a Cacaso, fazendo uso desse termo com relativa desconfiança, por falta de palavra mais apropriada, porém sem deixar de lembrar que há estudos em andamento que problematizam com muita propriedade seu uso. Referir-se à geração marginal se justifica apenas porque Cacaso esteve envolvido como criador e crítico nesses grupos que, por razões históricas, são reconhecidos por meio dessa nomenclatura. O termo geração, quando se refere à produção de obras, a grupo de escritores, não passa de um conceito-fetiche com o intuito deliberado de agrupar a diversidade dentro de uma unidade, seja ela histórica ou temática. O fato é que tal unidade geralmente não se sustenta. Basta dar uma olhadela no livro 26 poetas hoje, organizado por Heloísa Buarque de Hollanda, que, nos anos 1970, reuniu boa parte dessa produção, para perceber a pluralidade de temas e recursos. Como observa Pereira: "Esta solidariedade e esta identidade [...] não supunham uma maior homogeneidade no plano da linguagem poética de cada um. Eram, como afirma Geraldo E. Carneiro, cinco dicções, cinco poéticas diferentes"* Cada poética era construída à sua maneira, 
embora todas elas, em maior ou menor grau, tenham simulado o uso da língua na sua imediaticidade.

Por essa razão, o poema "Na corda bamba", de Cacaso, ao embaralhar a dualidade poesia escrita/poesia vivida, tornou-se uma espécie de palavra de ordem, funcionando como emblema das radicalizações promovidas por essa poesia:

Poesia

Eu não te escrevo

Eu te

Vivo

E viva nós!*

Aparentemente, tudo parece dito pela facilidade da construção de sentido, como se a frase prosaica apenas tivesse sido colocada na forma de versos, porém a inocência da palavra é usurpada pela estrofe isolada do corpo de quatro versos. A exclamativa em "E viva nós!" vem assinalada pela dificuldade de afirmar a função do "viva", a quem se direciona e dizendo o quê. É uma ovação, e daí caberia perguntar a quem se dar viva (quem é o "nós" nomeado? "Eu" e "outros"? "Eu" e a "poesia”?) ou é um imperativo do verbo "viver", mandando a outrem "nos viver”? Esse verso solitário, do modo ambíguo como é posto, pode modificar a primeira estrofe. Se considerarmos a primeira hipótese, "Eu te/ vivo" adquire outra significação em que "vivo" perde o sentido do verbo viver e passa a ser saudação (eu te/ vivo = eu te/ saúdo), afastando-a em termos da imediata adesão à experiência vivida. Por outro lado, não há nos dois primeiros versos tão-somente a negação narcisista do sujeito lírico à escrita, mas sim uma espécie de denegação, pois a escrita é negada, retira-se o próprio da escrita pelo ato de escrever, escrevendo. Há muito mais um virar às costas às imposições poéticas relacionadas a um modo homogêneo de perceber a escrita. Deixa-se de privilegiar suas regras, aproximando-a dos usos da fala. Não escrever não é se impor ao silêncio, mas questionar a razão do privilégio à escrita. Cacaso, em artigo sobre a poesia de Chacal, afirma que "[...] propor uma quase coincidência entre a poesia e a vida, isso resultaria, no limite, no desaparecimento, por desnecessidade, da própria poesia"** Entretanto, ao aprofundar esse gesto, ele não adere a um engodo niilista, mas antes marca as contradições de uma poesia que desejar estar à parte "de esquemas profissionais e do obscuro

\footnotetext{
"Todos os poemas de Cacaso foram retirados da edição de Lero-lero, publicada, na coleção Ás de colete, pelas editoras 7 Letras e Cosac \& Naify, em 2002.
}

\footnotetext{
" (Brito, A. C. F. de (Caca. so). Não quero prosa. Ob. cit.: 24-5).
} 
" (Hollanda, Heloisa Bu. arque de (org.). 26 poetas hoje. Rio de Janeiro: Aeroplano Editora, 2001 261). palavreado técnico dos cursos de literatura”. Sob esse aspecto, o trajeto poético de Cacaso põe na corda bamba o que convencionalmente se nomeia como poesia, não somente porque visa a uma comunicação com o público leitor, mas porque o faz por um processo mesmo de "desierarquização do espaço nobre da poesia”* . Mediante essa assertiva ambivalente (poesia/ eu não te escrevo/ eu te/ vivo), "Na corda bamba” sugere uma proposição nada fácil de aceitar, pois retirar a hierarquia do "espaço nobre da poesia” significa inevitavelmente questionar esse espaço e o modo como ele foi composto por conceitos homogêneos e totalizantes. Mesmo que haja algo de ingênuo nesse grito de ordem, ele revela que não pode haver uma definição prévia de literatura ou, dito de modo menos entusiástico, que sempre há modos de questionar definições. Embora seja de modo ambivalente, situar a poesia no campo do vivido, rompendo com a idéia de mímesis, como ela se configurou desde o momento fundador platônico, produz o deslocamento dos critérios pelos quais se norteava a poesia até aquele momento, mesmo que isso depois não se sustente como outra definição de poesia. Em outros termos, se a poesia, em vez de ser encenação do vivido, propõe-se a ser o próprio vivido, passa a ocupar outro lugar. Se esse outro lugar não se instaura sem conflitos, é importante descrever como ele se constrói.

\section{2.}

Por causa da inscrição num outro lugar, Cacaso foi desde o início um aglutinador de idéias, aquele responsável tanto por agrupar os mais jovens quanto por dar identidade ao que estava sendo feito em matéria de deslocamento de visão de poesia. Como afirmaram, ele era o teórico, aquele que explicava. Vem daí a idéia de poemão, relatada por Hollanda: “Cacaso na época dizia: 'Isto não é um movimento literário. É um poemão. É como se todos estivéssemos escrevendo o mesmo poema a 1.000 mãos"**

Assim, a entrega, espécie de engajamento a uma simulação da espontaneidade, ao mesmo tempo que altera a constituição da poesia de Cacaso, põe em discussão sucessivamente a própria linguagem da poesia, desdobrando de diversos modos a injunção de que a poesia está na corda bamba. O rompimento com a tradição imediatamente anterior ou mesmo com o que estava sendo produzido naquele momento - como a poesia concreta - se dá pela inscrição da poesia num campo próximo ao do desabafo, da piada, do bate-papo; essa proximidade com a trivialidade do 
cotidiano aponta o experimento com várias linguagens, e essa experimentação dá nova caracterização à palavra dita poética, que lhe parecia envelhecida, institucionalizada e fechada tanto quanto o campo editorial. Na edição completa de seus livros de poemas, em 2002, intitulada Lero-lero, é possível ver que, a cada novo livro, as palavras são mais exatas, à medida que o poeta passa a ser avarento em relação a elas. A minimização abriga a vida veloz, a leitura ligeira do seu tempo.

Nem sempre nosso poeta se comportou assim: desde os títulos dos poemas de A palavra cerzida, seu primeiro livro, a expressa influência vem do rigor formal de João Cabral de Melo Neto e de Murilo Mendes, e não da coloquialidade de Manuel Bandeira. Sonetos, madrigais, referências e dedicatórias a poetas como Drummond e Cecília Meireles, tudo faz crer que o poeta Cacaso queria se inserir na linha evolutiva da poesia brasileira. Nenhum questionamento como os que são vistos nos livros posteriores, seja na forma ou no conteúdo, indica que estava em jogo a busca de uma nova inscrição no panorama poético brasileiro. Logo, contudo, isso seria alterado, e pelo recurso simples do corte, como o que se dá em "Fábula", um dos poemas do livro:

Minha pátria é minha infância.

Por isso vivo no exílio.

Talvez o barco contasse deste percurso no tempo.

De como seria o escafandro isento de tal mergulho.

Minha pátria é sob a pele:

Cargueiro no mar de névoa. Antigamente os conflitos não aspiravam a ser.

De como fiquei trancado na torre em que era dono.

$\mathrm{E}$ a certeza como faca engolindo a própria lâmina.

De como se libertaram os mitos presos na forca, E o exato espanto vindo da terra, dos gestos do imperador. 
A atualização que Cacaso faz de "Canção do exílio", de Gonçalves Dias, texto já muitas vezes revisitado pela poesia brasileira, aponta a filiação a formas e temas tradicionais. As imagens do poema reforçam esse caráter, o que não quer dizer que na elaboração poética não há elementos próprios, mas sim que esse espaço próprio não estava sendo construído mediante uma sobrelevação da tradição. A proximidade com outros credos poéticos, como o simbolista ("De como fiquei trancado/ na torre em que era dono"), o parnasiano ("E a certeza como faca/ engolindo a própria lâmina”) e o modernista ("De como se libertaram/ os mitos presos na forca"), reforça a força do exemplo como motor para a sua poesia. Recompõe-se a cena de leitura na composição da escrita.

Seu lugar está assinalado quando situa a pátria no tempo mítico da infância, diferentemente do poema de Gonçalves Dias, o que expõe a inadequação ao presente do sujeito lírico, que é reconduzido a um tempo - antigamente - em que "os conflitos não aspiravam a ser”. O termo exílio passa a derivar não apenas o sentimento de estrangeiridade comum a quem está longe de sua terra, mas também a estranheza que habita em cada um, sob a pele. Preso às lembranças, num procedimento escapista romântico, o estado de exílio é mantido.

Nada mais revelador do que o reaparecimento desse poema no livro Na corda bamba, de 1978. Neste, a estética do fragmento dá forma aos novos ideais "marginais". Desde o uso, na epígrafe, da frase de El Rei Dom Manuel, a técnica do corte é anunciada: "Só pra ficar nu preciso de sete alfaiates". A formalidade poética cede espaço a um poema ligeiro, concentrado em um ou dois versos. Sai de cena o jogo discursivo de "Fábula" para a síntese prosaica de "Lar doce lar", novo título do poema: "Minha pátria é minha infância:/ Por isso vivo no exílio".

Cacaso reescreve sua obra cortando abruptamente o que considera supérfluo, palavroso, excessivo. A escolha por uma linguagem reduzida ao mínimo advém de uma "responsabilidade da escrita", que tem como uma de suas faces a retirada de qualquer obstáculo à recepção. Roland Barthes, num tex to que tem o sugestivo título de "Que é a escrita?", afirma que "Não é dado ao escritor escolher a sua escrita numa espécie de arsenal atemporal das formas literárias. É sob a pressão da História e

" (Barthes, Roland. O grau zero da escrita. São Paulo: Martins Fontes, 2000: 15). da Tradição que se estabelecem as escritas possíveis de dado escritor"*. Assim, fazer uma escolha implica distanciar-se de outras; acolher uma entre tantas é marcar a escrita com a sua 
assinatura, dar um caráter próprio àquilo que está exposto junto a outras marcas, a outras assinaturas, e é o que faz Cacaso. Ele faz isso optando por distanciar-se do padrão literário, neutralizando qualquer essência do literário. Para tanto, aponta para o que há de transitório e fugaz nas relações humanas. É a vez da conversa (e também da pausa):

PAPO FURADO [para Nilo de Oliveira]

$\mathrm{O}$ transcendental se dissolvendo no

Efêmero

No Dicionário Aurélio, efêmero, além dos significados costumeiros, aponta para outros sugestivos: "3. Diz-se da flor que fenece no próprio dia em que se abre. [...] 5. Insetos de vida curta, donde o nome, e que servem de alimento a pequenos peixes. Certas espécies vivem horas, apenas, e não se alimentam na fase adulta". Ora, um projeto estético que tende a dissolver o "muito elevado; superior, sublime, excelso" (cf. o verbete "transcendental" no mesmo dicionário) em uma flor ou inseto que dura pouco marca um abrupto rompimento com as leis do texto literário, pois este guarda na própria essência o sentido de durável. O que há de espontâneo no papo furado ganha novos matizes, que são resultado de um posicionamento estético claramente especificado tanto em seus textos de crítica quanto em seus livros de poesia.

A casualidade, o referencial, a contenção poética são recolocados na "ordem do dia". Por outro lado, num jogo dialético, também são assinaladas as contradições geradas por esse modo de fazer poético. O extremo do verso único pode vir, por exemplo, acompanhado por uma questão metalingüística que põe em jogo as proposições dessa nova poesia ("PASSOU UM VERSINHO voando? Ou foi uma gaivota?”). Aqui, há a perda da inocência que poderia estar enunciada no poema " $\mathrm{Na}$ corda bomba”. A forma persiste na sua miniaturização, mas o conteúdo afugenta o caráter afirmativo da intenção de unir vida e poesia. A proposta de transformar qualquer instantâneo em matéria de poesia é relativizada, deixando para o leitor, por meio dos pontos de interrogação, a decisão de escolher se aquilo é poesia ("Passou um versinho voando?") ou apenas mera pergunta (Ou foi uma gaivota?). A ironia contida nesse verso desestabiliza o próprio modo de ser marginal.

Dessa forma, a desarticulação da palavra poética termina por apresentar-se, ao mesmo tempo, como aproximação aos 
" (Siscar, Marcos. A cisma da poesia brasileira. Si. bila, Revista de Poesia e Cultura, n. 8-9, São Paulo, 2005: 41.60). ideais modernistas do começo do século XX e negação dos projetos concretistas da década de 1950, tendo que parecer que não defendia coisa alguma a não ser a alegria da produção. A dualidade entre o ser e o parecer está presente em todo corpo poético de Cacaso, desnudando a desconfiança a projetos totalizadores. Por isso, as mudanças não se configuram como regras predefinidas, obrigadas a se perpetuarem.

Tal desconfiança advém de outra característica da poesia de Cacaso: o não-distanciamento da cultura livresca. Embora o escritor tenha feito parte de uma geração de escritores que virou as costas para a cultura letrada, seus poemas revelam um movimento contrário, o de questionar os valores livrescos não por que os desconhece, mas por que, (re)conhecendo-os, atentam para a necessidade de enxertar neles outros valores.

\section{3.}

Para comprovar tal fato, podemos retomar a mais substancial polêmica para a afirmação dessa poesia, a que se deu entre a "forma" dos concretistas e o "conteúdo" dos marginais, como se a negação da primeira reafirmasse o segundo. Essa polêmica está fundada, entre outras razões, no pêndulo invisível que sustenta a poesia brasileira. É o que Siscar chamou de cisma espécie de sistema rígido que opõe poéticas distintas*. Em 1974, no livro que Cacaso publica na coleção Frenesi, Grupo Escolar, logo no corpo do primeiro poema, há mais uma vez uma espécie de manifesto: "Não quero meu poema apenas pedra/ nem seu avesso explicado/ nas mesas de operação”. O campo semântico da palavra "pedra", no caso da poesia brasileira, nos remete imediatamente a Drummond, como também às pedras do João Cabral, mas o embate que se estabelece aqui é com o rigor conceitual dos concretos, explícito em poemas como "Estilos de época”. Nesse livro, as marcas tradicionais da poesia (poemas longos, em geral) ainda estão presentes, mas já a serviço das "lições" marginais:

Havia

os irmãos Concretos

H. e A. consangüíneos

e por afinidade D. P., um trio bem informado:

dado é a palavra dado

$\mathrm{E}$ foi assim que a poesia

deu lugar à tautologia 
(e ao elogio à coisa dada)

em sutil lance de dados:

se o triângulo é concreto

já sabemos: tem 3 lados.

Nesse retângulo verticalizado, o verbo haver no passado, destacando-se sozinho no primeiro verso, dá-nos a idéia de que o fato "narrado" é datado, ocorrido num tempo longínquo. Está instaurado o tom de polêmica. O poema apropria-se da linguagem que não lhe pertence, que é a do outro, com o relativo uso dos recursos concretistas (parênteses, letras que indicam iniciais de nomes, numeral sem ser por extenso) e a alusão ao paideuma concretista para escarnecer os procedimentos dos concretos. O poema funciona como um espelho invertido, é aquilo que não quer ser, a sua negação.

Mostrar-se como contrário é aportar na ironia. Como afirmado, a poesia de Cacaso é derivada da aproximação a certo mundo e distanciamento de outro. Esses movimentos são ressaltados muitas vezes pelo recurso da ironia - entendo esta como o movimento que a linguagem faz para negar alguma coisa quando nos dá a impressão de estar afirmando-a e também "a toda a forma de gozo frio e analítico, aos sarcasmos enunciados com um tom impassível e falsamente destacado"*. Por excelência, esta definição serve exemplarmente para iluminar poemas como "Política literária” e "Estilos de época”. Neste, como vimos, tomar-lhe a forma, realçar os significantes e sua iconicidade à maneira dos concretos é negar essa forma por meio de uma linguagem que aparenta ser meramente explicativa. A ironia fica explícita, quando sabemos que a poesia de Cacaso, em vez do formalismo, defende a "marca suja” da vida e simula uma grande voz reivindicatória como a maneira encontrada para combater um mundo que lhe parece de todo insatisfatório. Daí a diferença abissal entre o poeta Cacaso e os concretos; uma questão de forma, mas também de valor.

De todo modo, seria um equívoco relacionar a poesia de Cacaso tão-somente a uma consciência teórica, pois seria o mesmo que afirmar uma poesia cerebral destituída das cores do mundo - o contrário do que ela é -, mas não é exagero acrescentar que poeta e crítico andam juntos no mesmo corpo do poema. Uma e outra atividade não se negam. Ler a sua poesia é ler a crítica, e vice-versa. Deriva daí o sentimento de work in progress, de transformações contínuas que vão a cada

"(Suhamy, Henry. As figuras de estilo. Portugal: Rés Editora, s/d: 142). 
novo livro invalidando a credibilidade do estatuto hierárquico da literatura. Por outro lado, o tom reivindicatório de alguns poemas, à medida que simula uma marca de identidade que reuniria um grupo de poetas, restringe o campo de atuação do escritor. Pode ter sido essa percepção que fez com que, em 1975, Cacaso publicasse um livrinho diferente tanto dos que ele já publicara como, em matéria de assunto, distinto dos livros de seus amigos poetas: Beijo na boca.

4.

É em Beijo na boca que se pode discutir mais demoradamente a suposta espontaneidade que geria a escrita dos poemas, pois nele há, no mínimo, um sujeito lírico que intermedeia a inserção das coisas cotidianas. É a deusa da reminiscência que comanda. Os poemas têm uma veia mais irônica, mais circunstancial, porém o tom polêmico que se conjugava com os textos críticos cede espaço a uma espécie de alheamento às coisas do mundo. Diversos poemas de amor dão o tom do lirismo, de modo que não há espontaneidade, mas sim a opção por uma linguagem próxima à prosaica, sem estar destituída de um ritmo intensamente marcado na colocação dos versos. As possibilidades do poema curto são experimentadas nas diversas acepções do discurso amoroso. De modo talvez mais contundente do que Manuel Bandeira, o tema do amor é dessacralizado, posto lado a lado das pequenezas cotidianas. É a forma de o sujeito lírico expor a sua individualidade, evocando um romantismo que marca o intervalo que o separa do mundo:

E COM VOCÊS A MODERNIDADE

Meu verso é profundamente romântico.

Choram cavaquinhos luares se derramam e vai

Por aí a longa sombra de rumores e ciganos.

Ai que saudade que tenho de meus negros verdes anos!

Afirmar a modernidade e declarar-se "profundamente romântico” é estar de todo fora-de-moda, especialmente numa época em que novas formas de relacionamento estavam sendo experimentadas e quase nenhum escritor do seu grupo poetizava o sentimento amoroso. Esse ponto foi pouco percebido na obra de Cacaso, mas, de fato, a temática amorosa atravessa-a por completo. Pela solidão que denota, falar a linguagem do amor 
é ser falado por ela, conformando-se assim um tom afirmativo: "Quando um discurso é dessa maneira levado por sua própria força à deriva do inatual, banido de todo espírito gregário, só lhe resta ser o lugar, por mais exíguo que seja, de uma afirmação"** Precisamente porque na poesia de Cacaso não há somente um discorrer de experiências cotidianas, ela também é envolvida pelo dispositivo da memória como recurso para a criação:

PROBLEMAS DE NOMENCLATURA

Rememoro com resignado e fervoroso amor

A primeira namorada.

Mas o nome dela dançou.

Em geral, tem-se a idéia de que o poema curto dispensa a memória, tornando-a desnecessária. A própria forma facilitaria o registro imediato, concomitante à experiência, porém o sujeito lírico, nesse poema de três versos, evoca a rememoração como condição para falar do amor e, conseqüentemente, para que o poema seja escrito, invertendo a ordem de valores que liga o espontaneísmo ao verso curto. Em outras palavras, equivale a afirmar que não há espontaneidade nem para dizer sobre o acontecimento, pois é preciso acionar a memória, nem para compor a forma do poema. A escolha das palavras, o modo de dispô-las nos versos, marca acentuadamente o ritmo, denotando um trabalho sobre a palavra, e não uma disposição aleatória de algo surgido espontaneamente. $\mathrm{O}$ uso reiterado dos sons de " $r$ " e " $m$ ” comprova isso. Assim, seria um equívoco afirmar que, no poema curto, aloja-se com mais facilidade o registro espontâneo do cotidiano.

O “problema” também não é só esquecer o nome do "resignado e fervoroso amor”. Nomear esse sentimento poeticamente, naquele momento, também constituía um intervalo no discurso de filiação a um grupo. Na voz do poema, todavia, também não é possível tratar desse tema de forma derramada. Para Cacaso, o amor é antes uma afirmação do sentimento, do objeto em si, sem necessariamente fixar-se em um sujeito. Segundo ele, "a identidade está cindida; os valores (inclusive os estéticos) carecem de credibilidade; as relações são fugazes; o amor é enganoso; o presente é urgente; o futuro é sombrio. A consciência torna-se desencantada e crítica”* Para um sujeito partido, amores igualmente de passagem, ausentes, apesar do persistente desejo de presentificação: "Cartesiana-daquele amor que
" (Barthes, Roland. Frag. mentos de um discurso amoroso. Rio de Janeiro: Francisco Alves, 2000).
" (Brito, A. C. F. de (Caca. so). Não quero prosa. Ob. cit.: 91). 
nunca tive tenho/ saudade ou esperança?". O amor "desencantado" se ajusta adequadamente à forma dos micropoemas, que se tornam fragmentos de um lirismo contido e indeciso entre a memória e o esquecimento. A imagem da mulher não é nomeada, podendo ser todas que passaram ou passarão pela vida do sujeito lírico. É o tema da instantaneidade, mas mediado pela lembrança. A ausência acarreta uma busca sem descanso, numa escolha sempre deixada para depois: "Penso em meu amor. Qual deles?” Ou então: "Muitas mulheres na minha vida./ Eu é que sei o quanto dói”.

Doar um lugar para o amor é, pois, negar o exterior, é caminhar por uma zona fronteiriça em que a presença desse sentimento anula outras paisagens. Retornamos àquele sentimento de estrangeiridade, em que o estar no mundo se realiza pela atopia, o não-lugar. Não há sinais de urbanidade nos versos românticos de Cacaso, e mesmo nos não-românticos. É uma poética avessa ao progresso, às conquistas tecnológicas; a sua modernidade deriva de outras formas de representação. Ao contrário de Mário de Andrade, que em Paulicéia Desvairada reafirma o moderno ligado à técnica pelo uso de palavras como "automóveis", "cinema" e "asfalto", Cacaso silencia; nada diz sobre. A cidade, os fatos, as polêmicas desaparecem, deixando apenas as várias faces de múltiplos amores. Vê-se uma desterritorialidade, como se a perplexidade do presente não pudesse ser descrita e a saída fosse voltar-se para o que, na poesia, já tinha sido o mais cantado dos sentimentos: "HAPPY END O meu amor e eu/ Nascemos um para o outro/ Agora só falta quem nos apresente". Em vez de olhar sobre as imagens da grande cidade, ao que acontece em volta, o cotidiano das lembranças compõe os mini-versos. Mesmo quando o mar aparece em Cacaso, não é o mar do Rio de Janeiro, local onde vivia, mas o mar de mineiro, como indica o título de seu último livro. É o mar da imaginação. Há, pois, uma hesitação entre o acolhimento na imediaticidade e a fuga desta.

Em Segunda classe, também de 1975, feito em parceria com Luis Olavo Fontes, livro de viagem em que compartilham anotações das paisagens e passagens que encontraram pelo caminho, também se desdobra o tema da memória pelo retorno à infância, colaborando para a idéia de desenraizamento. É ele mesmo quem nos diz: "O poema nasce perdido/ na infância", tema de Bandeira por excelência.

Percebe-se o quanto é difícil, na sua poética, separar o real da reelaboração desse real pelas palavras. Há uma intermedia- 
ção constituída pela própria imagem de Cacaso: o que há são entreatos, aquilo que não é mais representação (no sentido teatral), mas tampouco é factual. Como disse Roberto Schwarz, ele mesmo era uma personagem com sua bolsa a tiracolo, seus óculos de aro redondo, cabelos longos numa cara que permaneceu de menino. Era um matuto, como disseram alguns. Um matuto com saudade de casa, não a real, mas aquela que povoa nossas lembranças e nos constitui como sujeitos com passado:

IDADE DE OURO

Chiquinho encontrava no fundo da memória

uma vaca

Eva um pássaro

e ambos ainda se lembravam de um

caboclo que deambulava pelo bosque

[do idílio.

Mar de mineiro

Um poeta que, embora empenhado em negar o academicismo, faz uso de uma forma tradicional da poesia, nomeando-a (idílio), arrisca-se a ver sua escolha corrompida - e é todo esse risco que percorre Mar de mineiro, seu último livro. Tentar transformar o sublime no efêmero é, inclusive, não permanecer neste por muito tempo, sob a pena de repetir-se. É preciso, pois, dar a Cacaso o direito de deslocar-se, pois foi desse modo que ele experimentou várias linguagens. Não poderia haver e não há na poesia de Cacaso meros recortes de situações cotidianas; há uma inscrição, por vezes incisiva, por vezes suspensa, em outro campo da linguagem. Esse campo, não totalmente especificado, altera e deforma a visão poética, fazendo da "degeneração" não um fim em si mesmo, mas um meio para pôr em suspensão os critérios que norteiam os valores ditos literários. Como sabemos, a recusa da poesia contemporânea em deter-se sobre grandes temas, tratando do efêmero, de assuntos comuns do dia-a-dia, encontra suas referências em poetas como ele, e é isso o que marca a atualidade da sua poesia. 


\section{Milena Magalhães}

Doutoranda em Teoria da Literatura no Programa de Pós-Graduação em Letras da UNESP, campus de São José do Rio Preto. Bolsista do CNPq.

Palavras-chave

Cacaso

poesia marginal

simulacro de espontaneidade

Key words

Cacaso

marginal poetry

simulacrum of spontaneity

Mots-clé

Cacaso

poésie marginale

simulacre de spontanéité.
Recebido em 15/10/2005

Aprovado em 27/12/2005

\section{Resumo}

A partir da leitura de alguns poemas de Lero-lero, reunião da obra poética de Cacaso, este artigo interroga a visão de que a poesia marginal não tem relevância do ponto de vista literário, tendo sido constituída apenas pela expressividade espontânea dos acontecimentos cotidianos e prescindido de elaboração poética. Ao contrário, constata-se que os poemas de Cacaso apontam para a construção de um simulacro de espontaneidade sustentado não por um descuido formal, mas sim por uma depuração da linguagem que possibilita colocar na corda bamba os valores ditos literários.

\begin{abstract}
On reading the poetry in Lero Lero, a collection of Cacaso's poetical work, this article questions the supposition that marginal poetry has no literary value as it was created through spontaneous expression of dayto-day facts, overlooking poetical elaboration. On the contrary, Cacaso's poems point towards the construction of a simulacrum of spontaneity sustained not by a formal unconcern, but, yes, by a refined language, thereby placing the so-called literary values on a tightrope. Therefore we shall examine what this may mean and its effects.
\end{abstract}

\section{Résumé}

À partir de la lecture de quelques poèmes de Lero-lero, l'ensemble de l'oeuvre poétique de Cacaso, cet article interroge sur la vision que la poésie marginale n'a pas de valeur du point de vue littéraire, ayant été construite seulement par l'expressivité spontanée des événements quotidiens, se passant de l'élaboration poétique. Au contraire, on constate que les poèmes de Cacaso visent la construction d'un simulacre de spontanéité soutenu pas par une négligence formelle, mais par une dépuration du langage qui possibilite mettre sur la corde raide les valeurs dites littéraires. 